\title{
Uncertainties in Seismic Facies Analysis for Reservoir Characterisation or Monitoring: Causes and Consequences
}

\author{
P. Nivlet ${ }^{1}$ \\ 1 Institut Français du Pétrole, IFP, 1-4, avenue de Bois-Préau,92852 Rueil-Malmaison Cedex - France \\ e-mail: pniv@statoil.com
}

\begin{abstract}
Résumé - Causes et conséquences des incertitudes dans l'analyse de faciès sismiques pour la caractérisation et le monitoring de réservoir - Les techniques mutivariables probabilistes de reconnaissance des formes comme l'analyse discriminante proposent des solutions efficaces pour l'interprétation des données sismiques en termes de propriétés réservoir. Ces techniques permettent de calibrer une relation mathématique entre une information sismique locale (voxel sismique ou portion de trace extrait au niveau d'un réservoir) qui est décrite par un ensemble de caractéristiques ou attributs, et un ensemble pré-défini de classes appelées faciès sismiques. Dans le contexte de l'interprétation de données sismiques 3D, l'analyse discriminante fournit une carte (éventuellement un volume) de faciès le plus probable, permettant de décrire les principales hétérogénéités du réservoir détectables par la sismique. Ces dernières années, se sont également développées des applications de cette technique au monitoring sismique de réservoir. Dans ce dernier cas, chaque campagne sismique est interprétée en termes de faciès sismiques et les variations de l'interprétation d'une campagne à l'autre sont alors interprétées en termes de changements physiques du réservoir liés à la production.

L'analyse discriminante étant une méthode probabiliste, cela lui permet d'évaluer en partie l'incertitude associée à l'interprétation, cette probabilité pouvant être assimilée à une mesure de la confiance dans le classement de l'objet sismique. Cependant, cette vision de l'incertitude n'est que partielle. Dans ce papier, nous présentons trois autres aspects de l'incertitude intervenant dans l'analyse de faciès sismiques, et qui ne sont pas pris en compte par le modèle probabiliste utilisé. Le premier aspect est lié à la prise en compte des erreurs de mesures. Pour étudier la conséquence de telles erreurs sur le résultat du classement, nous proposons une méthodologie combinant calculs probabiliste et arithmétique d'intervalles, que nous appelons analyse discriminante par intervalles. Les deux autres aspects sont liés à l'interprétation des faciès sismiques en termes de changement fluide (dans le cas de l'interprétation de données sismiques 4D) ou d'hétérogénéités réservoir (dans le cas d'interprétation de la sismique 3D). Du fait de la différence de résolution entre la donnée sismique et les hétérogénéités réelles du réservoir, à une interprétation en facies sismique peuvent correspondre des scenarii géologiques décrits à l'échelle fine très différents. Nous montrerons comment la méthode des pseudo-puits peut-être utilisée pour mettre en évidence cette diversité d'interprétations. Nous montrerons également comment l'utilisation de la modélisation sismique peut, notamment dans le cas du monitoring sismique, aider à l'interprétation.
\end{abstract}

Abstract - Uncertainties in Seismic Facies Analysis for Reservoir Characterisation or Monitoring: Causes and Consequences - Multivariate probabilistic pattern recognition methods such as discriminant analysis are powerful for interpreting seismic data in terms of reservoir properties. They consist of calibrating a mathematical relationship between local seismic information (seismic voxels or pieces of 
traces extracted at a reservoir level), characterised by a set of measurements, named seismic attributes, and a pre-defined set of classes, named seismic facies. In the context of seismic reservoir characterisation, this methodology provides a map or a volume of most probable facies, which describes the main reservoir heterogeneities. During the last decade, another application of this technique to the interpretation of 4D seismic data has also emerged: in this case, each seismic vintage is interpreted in terms of seismic facies, and differences in the interpretation of one vintage from another are correlated a posteriori to production effects such as fluid substitutions or pressure variations.

As a probabilistic method, discriminant analysis allows the evaluation, at least partly, of uncertainty associated with seismic facies interpretation, and assignment probabilities computed by the methodology are a measure of the confidence of the interpretation. However, this uncertainty evaluation is only partial. In this paper, we will describe three other aspects of uncertainties, which are not correctly handled by classical discriminant analysis. The first aspect is linked with measurement errors. To propagate this type of error in seismic facies analysis, we have had to develop a methodology based on a combination of discriminant analysis and interval analysis. The other two aspects of uncertainty are linked with the interpretation of seismic facies. Due to the difference in resolution between seismic data in real reservoir heterogeneities, one seismic facies may correspond to several different fine-scale geological or dynamic scenarios. We will show in this paper how pseudo-well methodology, as well as seismic modelling (in the context of $4 D$ interpretation) can help address this issue

\section{INTRODUCTION}

Among the different techniques that have been developed for seismic reservoir characterisation and monitoring, seismic facies analysis plays a particular role. This methodology is based on pattern recognition techniques dedicated to interpreting seismic objects extracted from seismic data (multi-attribute voxels, or pieces of traces at a reservoir level) and described by a number of characteristics, or seismic attributes in a set of classes (Dumay and Fournier, 1988). These classes may be themselves related to geological heterogeneities (sandstones vs. shales) as in Bertrand et al. (2002), to petrophysical classes defined by cut-off values (e.g. porosity below 10\%) or to fluid properties (Lucet and Fournier, 2001). More generally, and due to the limited resolution of seismic data, seismic facies correspond to a combination of several of these factors. In the last decade, seismic facies analysis has been applied to many different issues, from reservoir characterisation (Nivlet et al., 2003) to seismic monitoring (Lucet and Fournier, 2001) and seismic anomaly detection (Marfurt, 2006).

A particularly interesting aspect of seismic facies is that this methodology allows one to answer jointly two types of questions, through the use of supervised and unsupervised methodologies:

- Supervised methodology aims at evaluating how similar seismic objects are to pre-defined groups, or training classes, which are formed of collections of already interpreted objects. For instance, these objects may be extracted close to cored well locations, where we have a direct access to local reservoir heterogeneity.

- Unsupervised methodology aims at detecting groups of objects with similar characteristics among all the seismic objects. This methodology allows the detection of seismic facies, which could have been missed by the training classes.
Beyond the interpretation that these techniques provide of seismic data, some of their implementations can also evaluate the uncertainty associated with the interpretation. For instance, discriminant analysis (Hand, 1981) is a supervised statistical technique, where the degree of similarity between seismic objects and training classes is expressed under the form of assignment probabilities. When the assignment probability of a particular seismic facies is close to 1 , it will give high confidence to the interpretation. On the contrary, when all the assignment probabilities associated with a given seismic object are low, the interpretation will be considered as less reliable. This uncertainty evaluation is very important, but also partial and incomplete. In this paper, we will show different aspects of uncertainties, which are not correctly handled by classical probabilities.

The first aspect is associated with seismic measurement error propagations: techniques such as discriminant analysis assume that seismic measurements are error-free. In reality, this assumption is far from being verified, due to the presence of different kinds of noises, which may be linked with acquisition, processing or wave propagation. We will show how to propagate seismic measurement errors by a combination of discriminant analysis with interval analysis (Moore, 1966).

A second aspect of uncertainty is the interpretation of seismic facies: even when performing supervised analysis, seismic facies analysis results may still need to be interpreted. This is the case for 4D seismic interpretation, where we need to understand a posteriori the changes in seismic facies interpretation from one seismic vintage to another. To address this issue, we need to combine 1D seismic modelling with production scenario assumptions.

Lastly, seismic facies analysis averages information vertically and extracts from this information the dominant geological or petrophysical character. However, this interpretation 
may not be sufficient to characterise critical heterogeneities of reservoirs, which are heterogeneities that control fluid flow and, therefore, recovery factor. We will show how pseudo-well methodology (Joseph et al., 1999) can help in displaying the different fine-scale heterogeneities that a single seismic facies can correspond to.

These different aspects of uncertainties will be discussed in two case studies. The first one is an effective 4D data interpretation: steam-assisted gravity drainage technology was used in a Canadian field in order to make the heavy oil mobile and producible. A baseline 3D survey describing initial reservoir conditions was first recorded. After, respectively, 18 and 24 months of continuous steam injection, two subsequent surveys were recorded in order to investigate the steam chamber localisation. Seismic facies analysis was then processed (Lucet and Fournier, 2001), the results of which will first be briefly commented on. The paper will then focus on analysing various aspects of uncertainties linked with these facies maps.

The last part of the paper, about fine-scale heterogeneity evaluation, is developed on the synthetic case study.

\section{SEISMIC FACIES ANALYSIS FROM 4D RAW AMPLITUDES}

Seismic facies analysis is a generic terminology to describe pattern recognition methods, which map seismic traces described by a set of characteristics or attributes extracted at the reservoir level, to a set of categories, or seismic facies (Dumay and Fournier, 1988). The calibrated relationship between attributes and facies is called a classification function. In the 4D context, attributes may be amplitude differences between base and subsequent monitor surveys, or raw amplitudes extracted from each survey. The methodology to interpret 4D seismic traces in terms of seismic facies is composed of the following steps:

- extraction of seismic attributes from each seismic trace in each seismic survey (11 successive amplitudes starting from the bottom of the reservoir);
- unsupervised seismic facies analysis to find the most frequent trace patterns, or seismic facies (8 seismic facies defined);

- selection of traces which are most representative from each seismic facies; selected traces are used as training samples for supervised facies analysis;

- supervised seismic facies analysis, consisting of:

. testing the quality of the calibrated classification function to identify seismic facies,

. classifying all the traces from any survey with this calibrated classification function.

To test the quality of the classification function, it is possible to compare in the training samples the initial seismic facies with the predicted one. This operation has led to values greater than $80 \%$ of correctly reassigned samples for each seismic facies. The calibrated classification function is therefore able to discriminate between the 8 facies defined. The last step of this workflow produces 8 probability maps $p\left(C_{i} \mid \mathbf{x}\right)$ for each survey, where $C i$ is one of the 8 seismic facies and $\mathbf{x}$, the 11-dimension attribute array extracted at a given position (Line; $C D P$ ). Finally, the results presented in Figure 1 are the most probable seismic facies maps. The interpretation of these maps will be discussed in detail later in the paper.

\section{CLASSICAL ESTIMATION OF UNCERTAINTY}

In the former analysis, Figure 1 represents the most probable seismic facies map: the seismic facies assigned to each trace has a maximal probability $p\left(C_{i} \mid \mathbf{x}\right)$. This probability, which is also called probability of good assignment, is a first view of uncertainties: the higher it is, the most confident the interpreter is with the assigned seismic facies. Figure 2 represents the 3 probabilities of good assignment maps. These probabilities are generally high, except at the boundaries between seismic facies, which indicates an overall good level of confidence in the interpretation. The lower probability traces correspond to transition zones between several facies, and are more difficult to assign precisely.

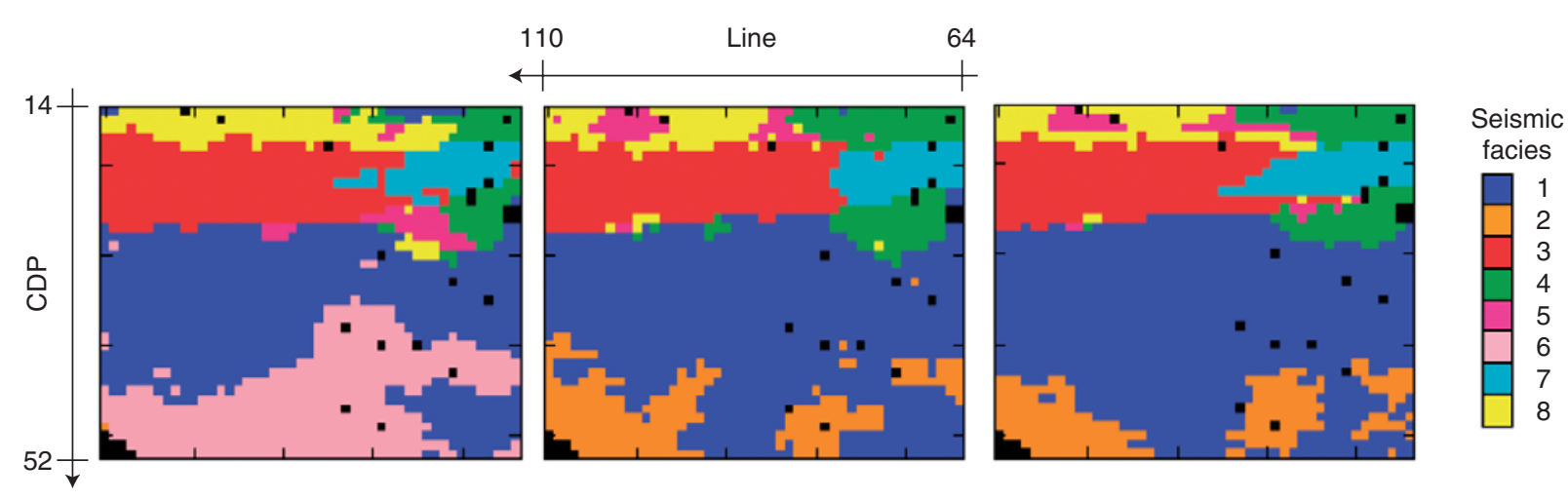

Figure 1

Seismic facies maps. 


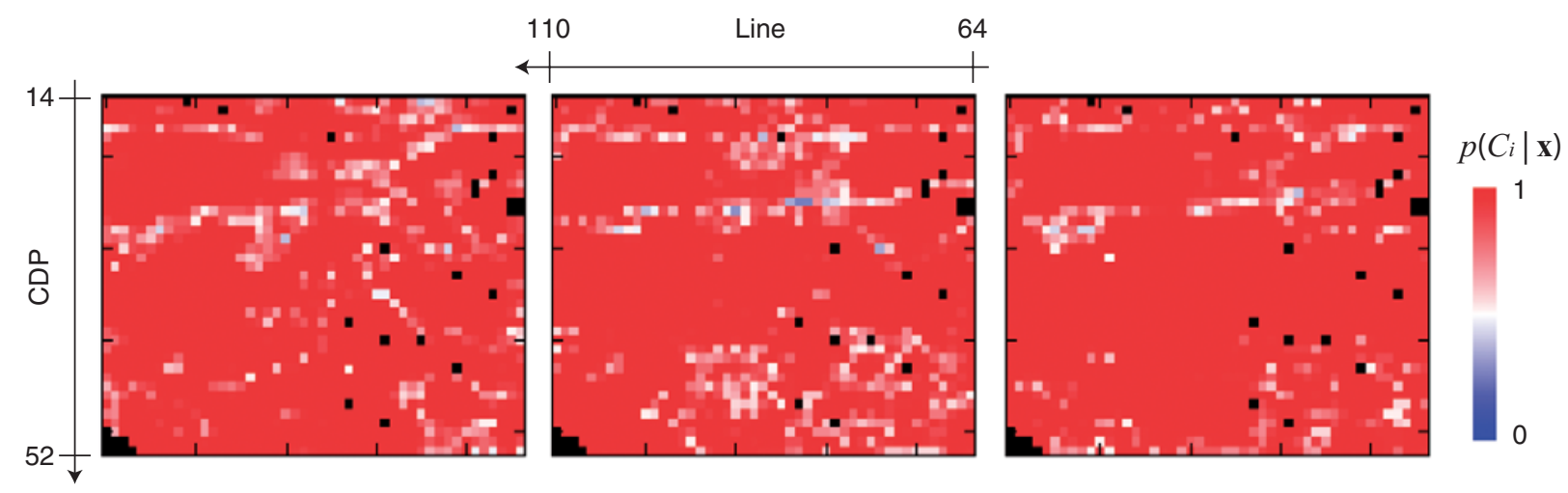

Figure 2

Probability of good assignment maps associated with seismic facies maps.

What kind of uncertainty do these probability maps capture? To answer this question, we have to recall that they are related to multivariate conditional probability density functions $(\mathrm{CPDF}) p\left(\mathbf{x} \mid C_{i}\right)$ through Bayes' rule:

$$
p\left(C_{i} \mid \mathbf{x}\right)=\frac{p\left(\mathbf{x} \mid C_{i}\right) p\left(C_{i}\right)}{\sum_{j} p\left(\mathbf{x} \mid C_{i}\right) p\left(C_{j}\right)}
$$

where $p\left(C_{i}\right)$ are the a priori probabilities for each seismic facies.

The CPDFs are computed from the training samples. When the number of training samples in each seismic facies is sufficient, non-parametric algorithms can be used to estimate CPDFs, to account for non-linear patterns, which is quite common in seismic interpretation. Silverman (1986) reviews some of these classical algorithms, among which are the kernel methods or the K-Nearest Neighbour. Otherwise, we have to make parametric (and simplifying) assumptions about the CPDFs: for example, we assume that CPDFs are multivariate gaussian with a conditional mean $m_{i}$ and a covariance matrix $S_{i}$ :

$$
p\left(\mathbf{x} \mid C_{i}\right)=\frac{1}{(2 \pi)^{p / 2}\left|S_{i}\right|^{1 / 2}} \exp \left\{-\frac{1}{2}\left(x-m_{i}\right)^{t} S_{i}^{-1}\left(x-m_{i}\right)\right\}
$$

In any case, the final probabilities $p\left(C_{i} \mid \mathbf{x}\right)$ depend on the assumptions made about the CPDFs, which have nothing to do with measurement errors in seismic attributes.

\section{IMPACT OF MEASUREMENT ERRORS}

In order to evaluate the impact of measurement errors, we used a technique based on a combination of discriminant analysis with interval analysis, which was first exposed in Nivlet et al. (2001). In this approach, seismic attributes $\mathbf{x}$ are supposed to be enclosed within a multivariate interval (or box) noted $[\mathbf{x}]$. The issue is to evaluate successively the ranges for the multivariate CPDFs $p\left(\mathbf{x} \mid C_{i}\right)$, noted $[p]\left([\mathbf{x}] \mid C_{i}\right)$; the ranges for the probabilities $p\left(C_{i} \mid \mathbf{x}\right)$, noted $[p]\left(C_{i} \mid[\mathbf{x}]\right)$; and the set of possible assignments $\left\{C_{j}\right\}$, when attribute arrays vary within boxes $[\mathbf{x}]$. For example, under the Gaussian assumption, we want to evaluate the following range:

$$
\left\{\begin{array}{r}
p\left(\mathbf{x} \mid C_{i}\right)=\frac{1}{(2 \pi)^{p / 2}\left|S_{i}\right|^{1 / 2}} \exp \left\{-\frac{1}{2}\left(x-m_{i}\right)^{t} S_{i}^{-1}\left(x-m_{i}\right)\right\} \\
\text { when } x \in[x], m_{i} \in\left[m_{i}\right], S_{i} \in\left[S_{i}\right]
\end{array}\right.
$$

The interval analysis techniques exposed in Moore (1966) give an approximate but realistic outer estimate for this interval. Then, Bayes' rule is extended to interval values using interval analysis expressions to compute the following expression:

$$
[p]\left(\left|C_{i}\right|[\mathbf{x}]\right)=\frac{[p]\left([\mathbf{x}] \mid C_{i}\right) p\left(C_{i}\right)}{\sum[p]\left([\mathbf{x}] \mid C_{j}\right) p\left(C_{j}\right)}
$$

Finally, the uncertain trace is assigned to the seismic facies, which has a dominating probability interval $[p]\left(C_{i} \mid[\mathbf{x}]\right)$ when it exists. When this interval does not exist because of overlapping between different $[p]\left(C_{i} \mid[\mathbf{x}]\right)$, all the seismic facies with non-dominating probability intervals are withdrawn from the solution set. The remaining seismic facies are the possible assignment for the uncertain seismic trace $[\mathbf{x}]$.

In order to run this workflow, we first have to evaluate the uncertainties in seismic attributes $[\mathbf{x}]$. Generally, these uncertainties are hardly ever known. However, in a 4D context, it is possible to examine inter-survey amplitude differences in zones, which are not impacted by reservoir production (such as zones above the reservoir). Normally, the amplitudes within these zones should not vary, in which case data would 
be perfectly repeatable. However, in real case studies, it is never the case, even after specific 4D reprocessing of seismic traces (Ross et al., 1996): Figure 3 shows the map of mean inter-survey amplitude differences evaluated from a constant time window extracted $100 \mathrm{~ms}$ over the produced reservoir interval. This map displays a strong horizontal non-stationarity.

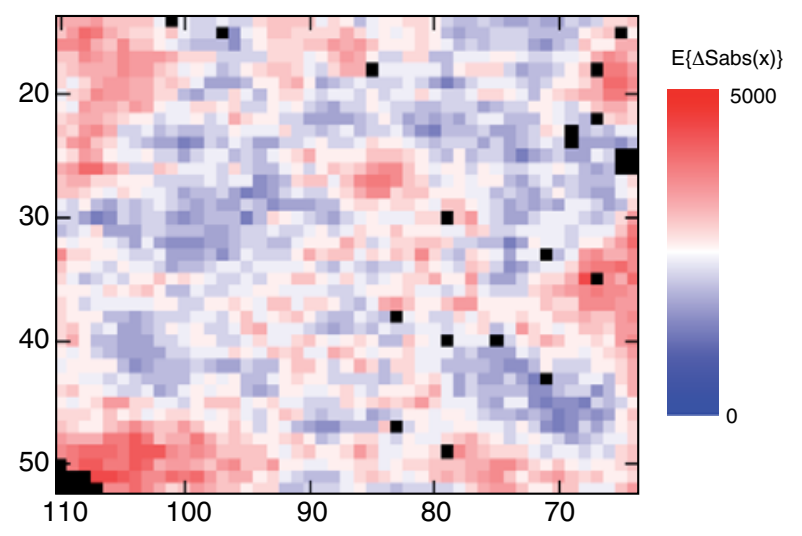

Figure 3

Mean horizontal variations of seismic amplitudes.

After checking the vertical stationarity of these uncertainties, and after checking that these uncertainties are not correlated with the mean inter-survey amplitude variations at the reservoir level, it was decided to consider this map as a good representation of data uncertainty.

To study the influence of seismic amplitude uncertainties on the interpretation results, we used the same training samples as those used in the first part of the paper. As in the standard classifying procedure, the first question we address is to know whether the training samples can be discriminated or not, among the 8 pre-defined seismic facies. Trying to reassign, with the calibrated interval classification function, the training samples to their original seismic facies does this. In Table 1, the lower bounds are the proportions of seismic traces correctly and uniquely reassigned by the interval algorithm, whereas the upper bounds correspond to the proportions of seismic traces where the interval classification analysis algorithm reassigns them to several classes, among which there is the correct class. These seismic traces are imprecisely reassigned.
The width of these intervals quantifies the impact of the uncertainties on the quality of the discriminant function. For example, seismic facies 2 has a wide interval, indicating that it cannot be precisely discriminated from the other ones. For the other seismic facies, the impact of the uncertainties is low (facies 3, 4, 6 and 7) to moderate (facies 1, 5 and 8).

The interval classification function is then used to predict the seismic facies for each seismic trace and each of the three surveys. We have represented in Figure 4 only the traces uniquely assigned. This figure allows a direct visualisation of the bins for which the seismic facies interpretation remains reliable even after taking the data uncertainties into account. We first notice that the interval algorithm uniquely assigns the great majority of the seismic traces. The uncertainties thus have a moderate effect on the assignment process. Furthermore, the interpretation of the first base survey is very precise, which indicates that the heterogeneity of the reservoir before steam injection is very well described by the discrimination among 8 seismic facies. After steam injection, the interpretation of the southern part of the reservoir does not remain precise. This lack of stability is a little disappointing, because changes in seismic facies noted in this zone may be connected with the growth of the steam chamber. Yet, Figure 5 attenuates this pessimism. It maps the possible extensions of seismic facies 1,2 and 6, where the interval discriminant analysis predicted a multiple facies. This figure confirms that seismic facies 6 disappears after steam injection. Moreover, the southern part of the reservoir can be assigned only to seismic facies 1 or 2 . In both cases, these facies are related to swept sandstones. Taking into account uncertainties thus has an impact on the interpretation between the seismic facies 1 and 2 .

\section{UNCERTAINTIES IN THE PHYSICAL INTERPRETATION OF SEISMIC FACIES CHANGES}

The third aspect of uncertainties in the 4D workflow derives from the physical interpretation and validation of the changes in seismic facies predicted during the production. This step is done at the well position by a feasibility study, which considers log data recorded before the start of the production and dynamic data (pressure and saturation) as inputs to a petro-acoustic toolbox to model changes in log data during the production. Then, a seismic modelling step allows the computing of synthetic traces corresponding to each seismic survey. Finally, a classification of these traces by statistical pattern recognition models changes in seismic facies during production.

TABLE 1

Correctly reassigned training sample proportion by interval discriminant analysis

\begin{tabular}{c|c|c|c|c|c|c|c|c}
\hline Seismic facies & 1 & 2 & 3 & 4 & 5 & 6 & 7 & 8 \\
\hline$\%$ & {$[73 ; 100]$} & {$[38 ; 100]$} & {$[90 ; 100]$} & {$[84 ; 100]$} & {$[72 ; 100]$} & {$[93 ; 100]$} & {$[95 ; 100]$} & {$[65 ; 100]$} \\
\hline
\end{tabular}




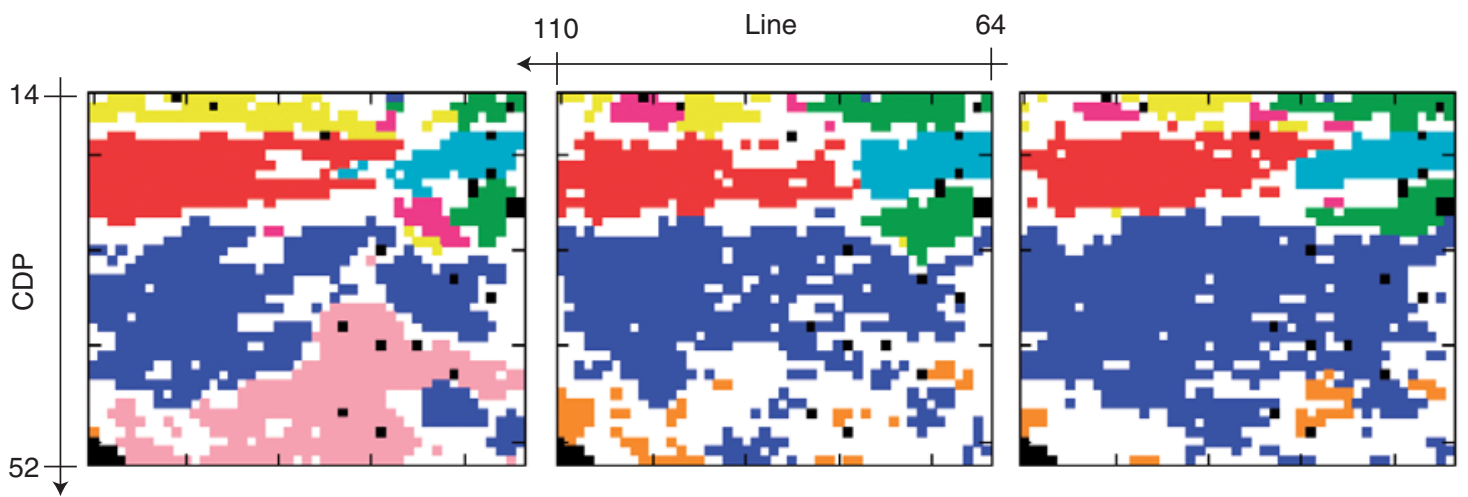

Uniquely

predicted seismic facies

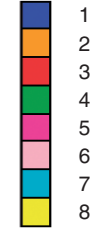

Non-uniquely predicted seismic facies

Figure 4

Impact of 4D non-repeatability on the result of seismic facies analysis.
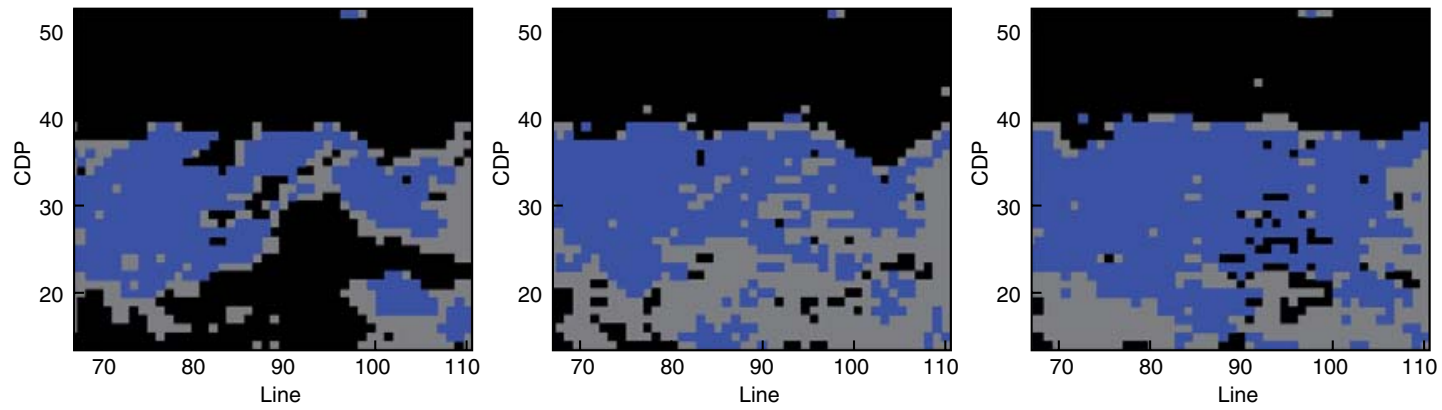

Seismic facies 1 Unique predicted facies Non unique
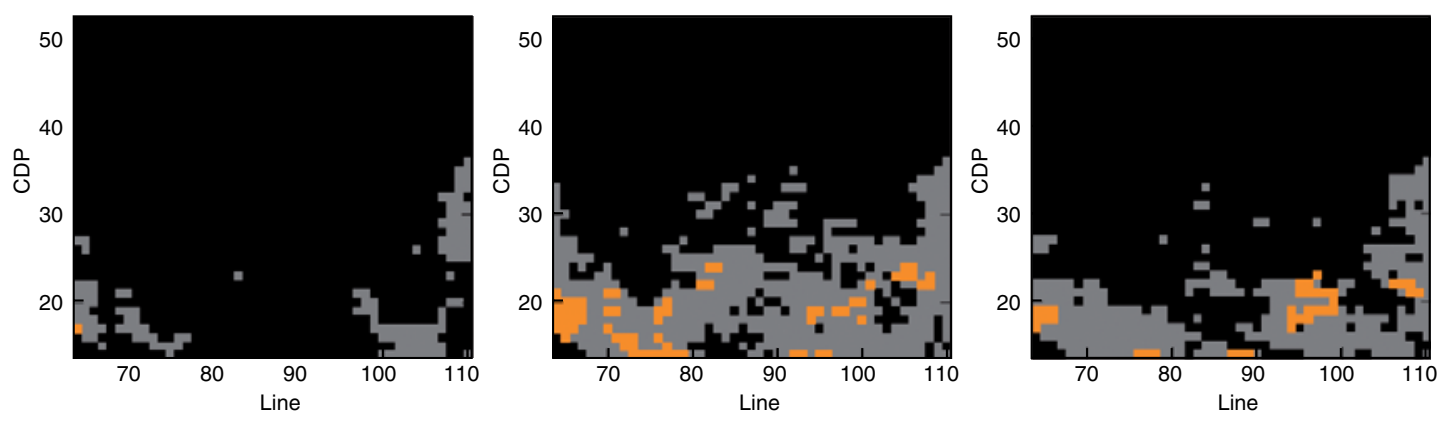

Seismic facies 2 Unique predicted facies

Non unique predicted facies
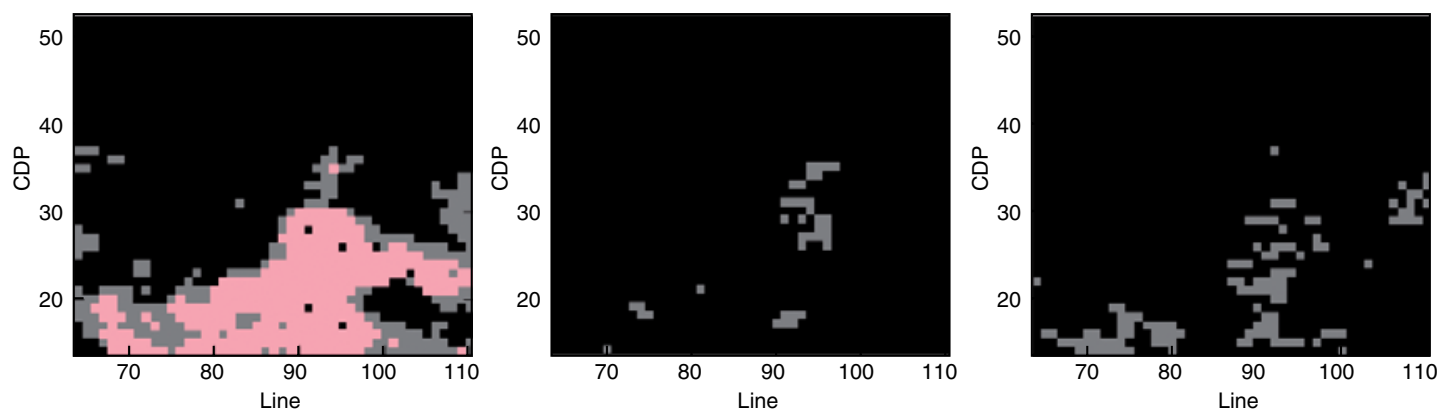

Seismic facies 3 Unique predicted facies

Non unique predicted facies

Figure 5

Impact of 4D non-repeatability on the result of seismic facies analysis: indicator functions for seismic facies 1, 2 and 6 in each survey (left = base survey; centre and right $=$ repetitive surveys). 


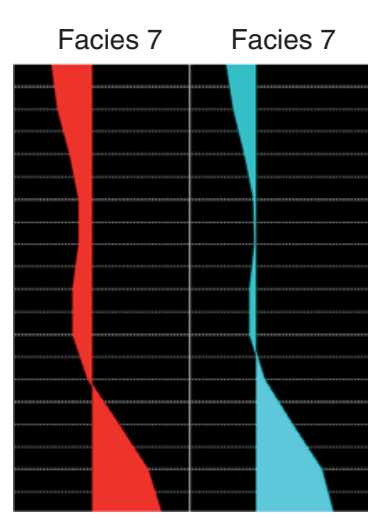

Well W1 Impedance synthetic

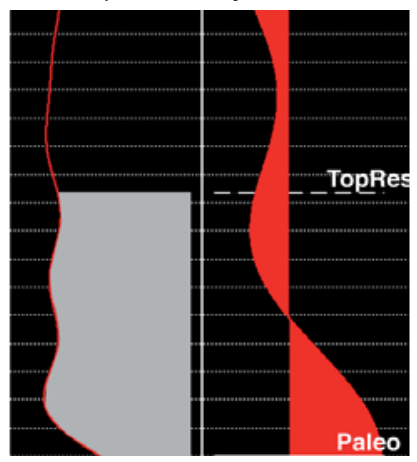

Facies 1
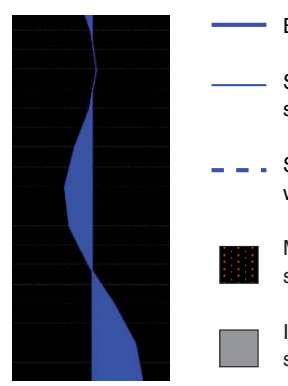

Before injection

Steam in massive sandstone

- - . Steam in the whole reservoir

Massive

sandstones

Interbedded

sandstones

Figure 7

Impedance and synthetic trace associated with well W2 (massive reservoir) before and after steam invasion compared with trace representative of seismic facies 1.
Well W2 Impedance synthetic

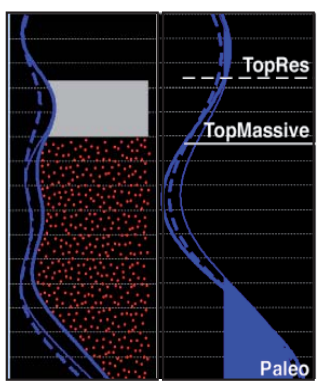

Impedance and synthetic trace associated with well W1 (non-reservoir) compared with traces representative of seis-

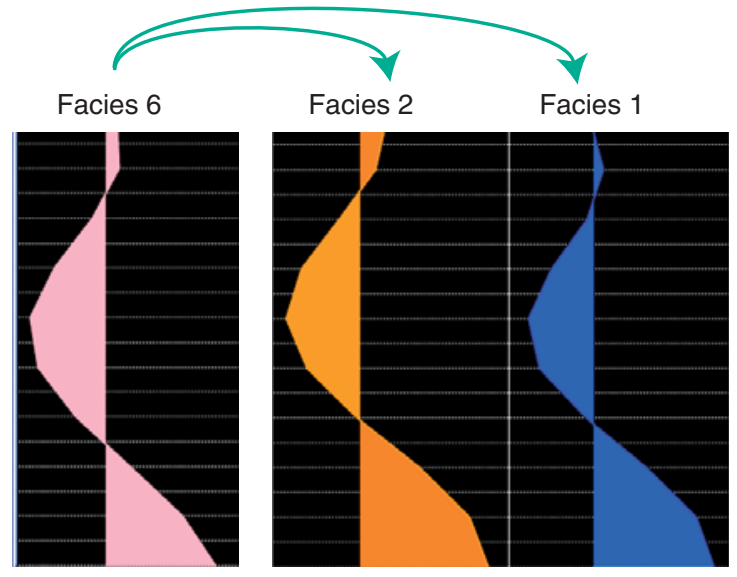
mic facies 3 and 7.

Figure 6 
we can conclude that in the intermediate reservoirs, we are able to identify partially swept zones from totally swept zones. In the good reservoir zone, an uncertainty still remains, because this facies is insensitive to its fluid content.

\section{UNCERTAINTIES IN THE GEOLOGICAL INTERPRETATION OF SEISMIC FACIES}

When performing facies analysis on a particular reservoir level, we integrate seismic information over a given time window. The resulting seismic facies map is therefore an average view of heterogeneities (which themselves may be due to a combination of geological, fluid and diagenetic heterogeneities). If we want to go a little further in the characterisation of reservoirs, we may want to characterise the distribution of geological heterogeneities on a fine scale corresponding to each seismic facies. Addressing this issue can then allow the computing of a fine-scale geological model consistent with the seismic information, which may be mandatory, for instance, for addressing fluid flow simulation problems. For instance, Doligez et al. (2003) propose a methodology of using seismic facies maps together with assignment probability maps as a guide to interpolate vertical proportion curves, which correspond to the average vertical geological trend. In this approach, vertical proportion curves derived from wells are duplicated in positions with similar seismic facies and sufficiently high probability. The resulting vertical proportion curve matrix, formed by the juxtaposition of all the vertical proportion curves at any position of the reservoir base map, is then used as a non-stationary constraint to the geological modelling, the fine-scale heterogeneities being described by a 3D variogram model.

In this paragraph, we intend to address a less general issue. However, the presented methodology could potentially improve the geological modelling phase. The issue is simply to try to characterise vertical heterogeneity statistical distributions corresponding to each seismic facies. After having performed seismic facies analysis, a first comparison may be done at well positions. The problem is that in most cases, well information is too scarce to characterise fully the variety of geological vertical trends corresponding to a given scenario. For instance, in the most probable seismic facies map displayed in Figure 9, 5 seismic facies have been interpreted. In the best case, we have only two wells falling in the same seismic facies zone. In the worst case, we have no well, as for the orange seismic facies.

In order to be able to have some plausible geological representation corresponding to this seismic facies (and also in order to have a more reliable estimation of the vertical variations in the other case), we propose to apply a pseudo-well methodology (Joseph et al., 1999), which aims at generating by geostatistical algorithms new well data, composed of possibly a lithological column and attached well logs.

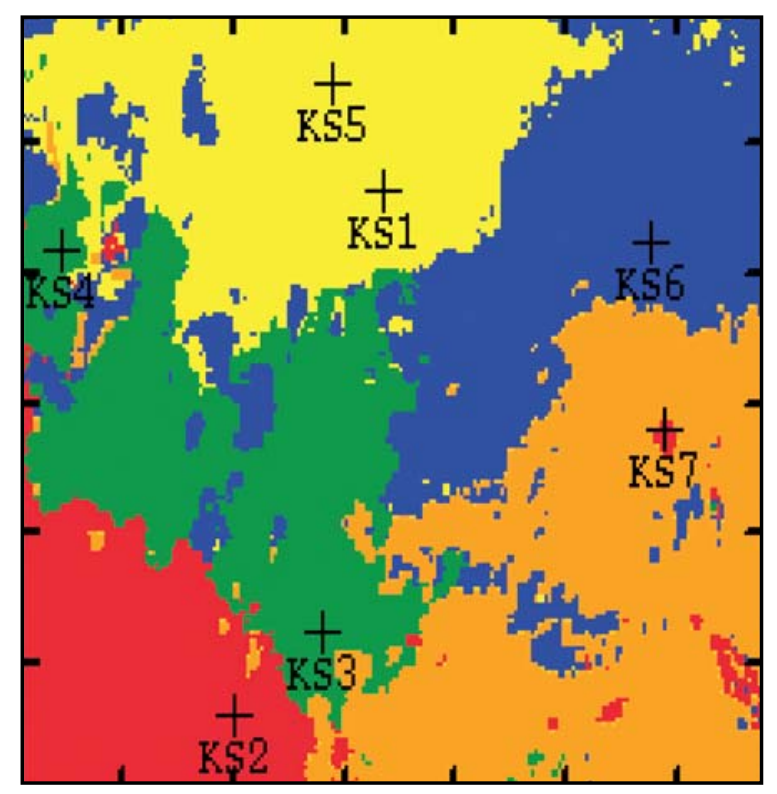

Figure 9

Example of most probable seismic facies map obtained from amplitudes extracted at a reservoir level.

The algorithm that we propose is composed of 4 main steps:

- Definition of well groups: the wells from each well group are supposed to be drilled in the same geological setting. This means that vertically, we should observe the same sequences of sediments. During this phase, wells from the same group should be easily correlated. When necessary, correlation between these wells should account for regional discontinuities (erosional surfaces, etc.) marked at each well, these markers defining themselves as homogeneous units, in which the sedimentary process may be described by a simple mechanism.

- Definition of (geo-)statistical constraints describing the vertical succession of sediments in each geological unit: these constraints concern first the geological facies themselves, through global facies proportions computed from well data about each geological unit, or through vertical proportion curves, which give the average facies vertical evolution for a given geological unit. Then additional constraints may be added if necessary, describing the vertical evolution of reservoir parameters such as velocities, densities, etc. These last properties are described in wells on a fine scale from well logs. Constraints are expressed under the form of global statistics, or global statistics for geological facies (mean, variance, etc.), and spatial statistics such as variograms, which are defined as the mean square of property variations expressed as a function of the distance, or lag, between these two points. 


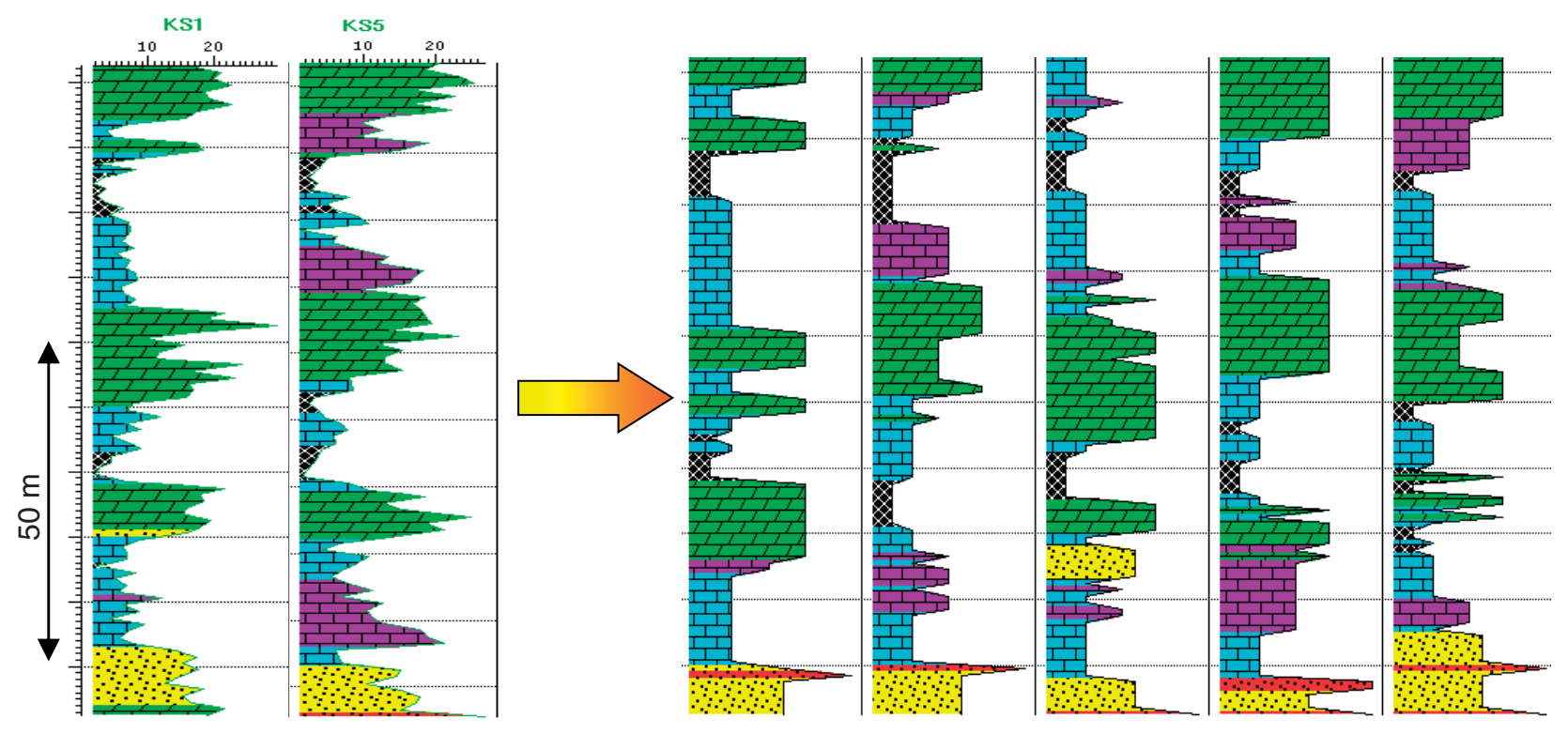

Figure 10

Example of pseudo-wells simulated from the KS1 + KS5 well group.

- Geostatistical simulations of pseudo-wells: classical geostatistical simulation algorithms are used to simulate additional well data. Concerning facies, Sequential Indicator Simulations (Deutsch and Journel, 1992) are used to produce random lithological columns which reproduce the main statistics described in step 2. Concerning the other properties, other algorithms may be used, such as sequential Gaussian simulations, random simulations, etc. This simulation step allows the generation of a number of well data with geological facies and the attached well log described on a fine scale. Figure displays some of the simulated lithofacies columns simulated from a well group composed of the wells KS1 and KS5 displayed on the left-hand side of Figure 10.

- Seismic attribute generation: from the simulated pseudowells, the goal is now to generate seismic attribute traces. The techniques involved to achieve this goal differ, depending on the goal of the study. For instance, if seismic amplitudes had been used during seismic facies analysis, the following sequence would have to be used:

- upscaling and resampling and simulated acoustic impedance pseudo-logs to the seismic scale;

- convolution of reflectivities derived from acoustic impedances with a wavelet.

- The seismic traces generated from pseudo-well realisations are then used as if they were true seismic traces to be interpreted by seismic facies analysis. The result of this interpretation can be a single seismic facies representative of a given reservoir level if seismic facies analysis had been performed in $2 \mathrm{D}$, or a column of seismic facies if seismic facies analysis had been applied in 3D, directly on seismic voxels.

- The different realisations of interpreted pseudo-wells are then grouped according to the assigned seismic facies. Figure 11 displays, for instance, all the lithofacies realisations associated with pseudo-wells that have been assigned to the orange seismic facies. This analysis shows that this orange facies corresponds mainly to an upward trend from yellow facies to green and blue, corresponding to a fining upward sequence. However, it also shows that some dispersion exists around this general trend: the massive yellow reservoirs may be compartmentalised into two or more sub-units.

\section{CONCLUSION}

We have shown in this paper the effects of different sources of uncertainties on the results of a seismic facies analysis. Traditionally, uncertainty is accounted for through probabilistic computations. These probabilities reflect the partial knowledge of the behaviour of a system: for instance, with discriminant analysis, the main goal is to assign objects to different classes, based on a calibration between attributes and classes. Probabilities account for two uncertainty causes: first, that the training sample does not cover the whole attribute space, and second, that there may be partly inconsistent information in the training sample. In some situations, this source of uncertainty may be dominant. However, this 

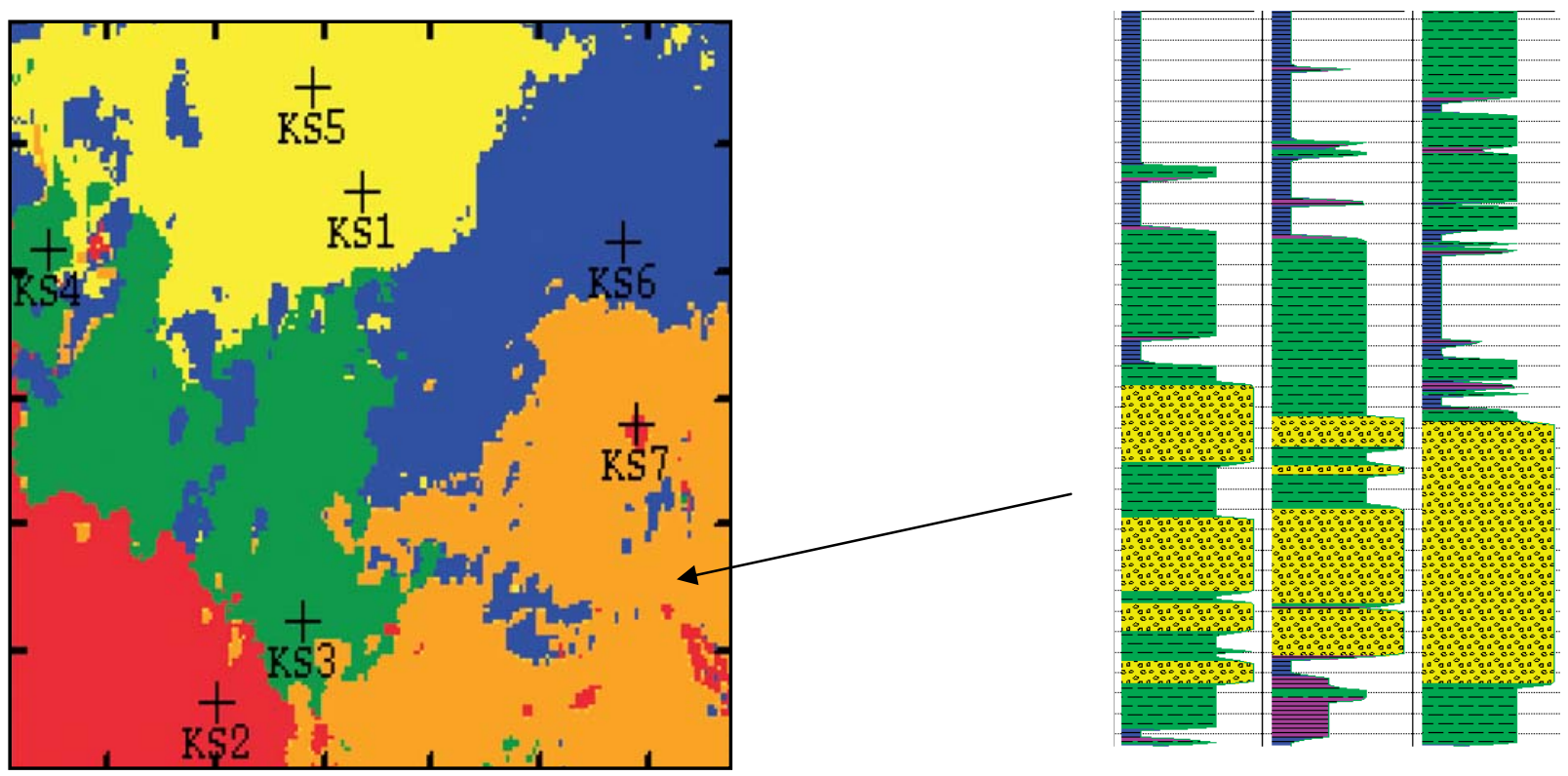

Figure 11

Three pseudo-wells assigned to the orange facies.

probabilistic approach has its limitations: it does not take into account measurement errors. In the case of seismic data, these errors may be, at least locally, very important. Their causes may be diverse, from acquisition footprints to unwanted wave propagation effects (multiples) or processing errors. We have presented a way to incorporate these errors into classical discriminant analysis. In the 4D example, we have shown that these errors make the interpretation less certain, but also more reliable. It can also help define the risk associated with the use of $4 \mathrm{D}$ interpretation in reservoir management. The other types of uncertainty are linked with the physical or geological interpretation of seismic facies. A first way to tackle this issue is to try to model seismic traces from available well data. In the 4D case, we can try to model possible production scenarios and therefore understand how the seismic signal evolves with time. However, this approach is very qualitative. To be more quantitative, we have presented a methodology based on pseudo-well simulations. This methodology provides a way to display the different possible vertical successions of sediments. Therefore, it provides a way to have a more quantitative interpretation of seismic traces and to facilitate their integration in reservoir characterisation workflow.

\section{ACKNOWLEDGEMENTS}

The author would like to acknowledge Nathalie Lucet, Frederique Fournier and Benoit Andrieux from the IFP who have participated in different aspects of the interpretation of the case studies presented in this paper. Encana is also acknowledged for giving permission to publish the real case study on the East Senlac reservoir.

\section{REFERENCES}

Bertrand, C., Tonellot T., and Fournier F. (2002) Seismic facies analysis applied to $\mathrm{P}$ and $\mathrm{S}$ impedances from prestack inversion: 72nd Ann. Internal. Mtg, Soc. Expl. Geophys., Expanded Abstracts, 217-220.

Deutsch, C.V. and Journel, A.G. (1992) GSLIB: Geostatistical Software Library. Oxford University Press, New York.

Doligez B., Gomel P., Andrieux B, Fournier F. and Beucher, H. (2003) Use of seismic to constrain geostatistical reservoir models: a quantitative approach using proportions of facies. AAPG Ann. Mtg., Proceedings.

Dumay, J. and Fournier, F. (1988) Tutorial on multivariate statistical analyses applied to seismic facies recognition. Geophysics, 53, 1151-1159.

Hand, D. J. (1981) Discrimination and classification, Wiley Series in Probabilities and Mathematical Statistics, John Wiley \& Sons, Chichester.

Joseph, C., Fournier, F., and Vernassa, S. (1999) Pseudowell methodology: A guiding tool for lithoseismic interpretation, 69th Ann. Internal. Mtg., Soc. Expl. Geophys., Expanded Abstracts, 938-941.

Lucet, N. and Fournier, F. (2001) 4D data interpretation through seismic facies analysis, 71st Ann. Internal. Mtg., Soc. Expl. Geophys., Expanded Abstracts, 1640-1643.

Marfurt, K.J. (2006) Seismic attributes mapping of structure and stratigraphy, SEG-EAGE DISC Course, Soc. of Expl. Geophys., Tulsa. 
Moore, R. E. (1966) Interval analysis, Prenctice-Hall, Englewood Cliffs.

Nivlet, P., Fournier, F., and Royer, J-J. (2001) A new methodology to account for uncertainties in 4D seismic interpretation, 71st Ann. Internal. Mtg., Soc. Expl. Geophys., Expanded Abstracts, 1644-1647.

Nivlet, P., Tonellot, T., Schwedersky-Neto, G. and Dos Santos, M.S. (2003) Joint pre-stack stratigraphic inversion and facies analysis on a Brazilian deep offshore field, 8th International congres of the SBGf, Expanded Abstracts.
Ross, C-P., Cunningham, G-B. and Weber, D-P. (1996) Inside the cross-equalization black-box, The Leading Edge, 15(11), 1233-1240.

Silverman, B. W. (1986). Density estimation for statistics and data analysis, Monographs on Statistics and Applied Mathematics, Academic Press, New York.

Final manuscript received in July 2006

Copyright (C) 2007 Institut français du pétrole

Permission to make digital or hard copies of part or all of this work for personal or classroom use is granted without fee provided that copies are not made or distributed for profit or commercial advantage and that copies bear this notice and the full citation on the first page. Copyrights for components of this work owned by others than IFP must be honored. Abstracting with credit is permitted. To copy otherwise, to republish, to post on servers, or to redistribute to lists, requires prior specific permission and/or a fee: Request permission from Documentation, Institut français du pétrole, fax. +33147527078 , or revueogst@ifp.fr. 